\title{
SCIENTIFIC REP

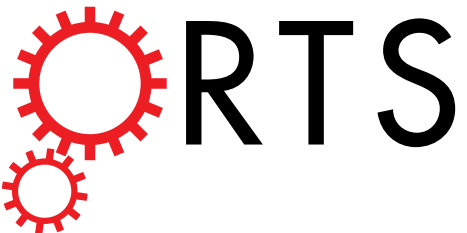 \\ Author Correction: Quantitative shadow compensated optical coherence tomography of choroidal vasculature
}

\author{
Kiran Kumar Vupparaboina ${ }^{1,2}$, Kunal K. Dansingani ${ }^{3}$, Abhilash Goud ${ }^{4}$, Mohammed Abdul \\ Rasheed $^{5}$, Fayez Jawed ${ }^{6}$, Soumya Jana2 ${ }^{2}$ Ashutosh Richhariya ${ }^{1}$, K. Bailey Freund $\mathbb{D}^{7,8}$ \& \\ Jay Chhablani ${ }^{5}$
}

Correction to: Scientific Reports https://doi.org/10.1038/s41598-018-24577-8, published online 24 April 2018

The original version of this Article contained a typographical error in the name of the author K. Bailey Freund, which was incorrectly given as Bailey K. Freund. This has now been corrected in the PDF and HTML versions of the Article.

The Author Contributions section now reads:

"Conception and design: K.K.V.; K.K.D.; S.J.; A.R.; K.B.F.; J.C. Data collection: A.G. Analysis and interpretation: K.K.V.; K.K.D.; A.G.; M.A.R.; M.F.J.; S.J.; A.R.; K.B.F.; J.C. Writing the article: K.K.V.; K.K.D.; A.G.; S.J.; J.C. Critical revision of the article: K.K.D.; S.J.; A.R.; K.B.F.; J.C. Final approval of the article: K.K.V.; K.K.D.; A.G.; M.A.R.; M.F.J.; S.J.; A.R.; K.B.F.; J.C.”

This has now been corrected in the PDF and HTML versions of the Article.

(i) Open Access This article is licensed under a Creative Commons Attribution 4.0 International cc) License, which permits use, sharing, adaptation, distribution and reproduction in any medium or format, as long as you give appropriate credit to the original author(s) and the source, provide a link to the Creative Commons license, and indicate if changes were made. The images or other third party material in this article are included in the article's Creative Commons license, unless indicated otherwise in a credit line to the material. If material is not included in the article's Creative Commons license and your intended use is not permitted by statutory regulation or exceeds the permitted use, you will need to obtain permission directly from the copyright holder. To view a copy of this license, visit http://creativecommons.org/licenses/by/4.0/.

(C) The Author(s) 2018

${ }^{1}$ Surjana Center for Innovation, LV Prasad Eye Institute Hyderabad, Hyderabad, Telangana, India. ${ }^{2}$ Department of Electrical Engineering, Indian Institute of Technology Hyderabad, Hyderabad, Telangana, India. ${ }^{3}$ Department of Ophthalmology, University of Pittsburgh Medical Center, Pittsburgh, Pennsylvania, USA. ${ }^{4} \mathrm{Clinical}$ Research, LV Prasad Eye Institute Hyderabad, Hyderabad, Telangana, India. ${ }^{5}$ Vitreo-retinal Service, LV Prasad Eye Institute Hyderabad, Hyderabad, Telangana, India. ${ }^{6}$ Truhlsen Eye Institute, University of Nebraska Medical Center, Omaha, NE, United States. ${ }^{7}$ Vitreous Retina Macula Consultants of New York, New York, New York, USA. ${ }^{8}$ LuEsther T. Mertz Retinal Research Center, Manhattan Eye, Ear and Throat Hospital, New York, New York, USA. Correspondence and requests for materials should be addressed to J.C. (email: jay.chhablani@gmail.com) 